\title{
Use of statins and the incidence of type 2 diabetes mellitus
}

\author{
André Bernardi ${ }^{1}$, Viviane Zorzanelli Rocha ${ }^{2}$, José Rocha Faria-Neto ${ }^{1 *}$ \\ ${ }^{1}$ Centro de Epidemiologia e Pesquisa Clínica (EpiCenter) - Escola de Medicina, Pontifícia Universidade Católica do Paraná (PUC-PR), Curitiba, PR, Brazil \\ ${ }^{2}$ Unidade de Lípides - Instituto do Coração (InCor)/Faculdade de Medicina, Universidade de São Paulo (FMUSP), São Paulo, SP, Brazil
}

Study conducted at EpiCenter, Pontifícia Universidade Católica do Paraná (PUCPR), Curitiba, PR, Brazil. All authors contributed equally for the production of this article

Article received: $7 / 15 / 2015$ Accepted for publication: $7 / 16 / 2015$

*Correspondence: Address: Av. Getúlio Vargas, 2932, cj. 1101 Curitiba, PR - Brazil Postal code: $80240-040$ jose.faria@pucpr.br

\section{SUMmarY}

Introduction: the use of statins is associated with reduced cardiovascular risk in studies of primary and secondary prevention, and the reduction is directly proportional to the reduction of LDL-cholesterol. Recent evidence suggests that statins may be associated with a higher incidence of new cases of diabetes. The aim of this review is to explore this possibility, identifying factors associated with the increase in risk and the potential diabetogenic mechanisms of statins. In addition, we evaluated if the risk of diabetes interferes with the reduction in cardiovascular risk achieved with statins.

Methods: we reviewed articles published in the Scielo and Pubmed databases, which assessed or described the association between use of statins and risk of diabetes up to June 2015.

Results: use of statins is associated with a small increase in the incidence of new cases of diabetes. Age, potency of statin therapy, presence of metabolic syndrome, impaired fasting blood glucose, overweight and previously altered glycated hemoglobin levels are associated with increased risk of diabetes, but there is no consensus about the possible diabetogenic mechanisms of statins. In patients candidate to hypolipemiant drug therapy, the benefit of reducing cardiovascular risk outweighs any risk increase in the incidence of diabetes.

Conclusion: statins are associated with a small increase in incidence of diabetes in patients predisposed to glycemic alteration. However, since the benefit of cardiovascular risk reduction prevails even in this group, there is no evidence to date that this finding should change the recommendation of starting statin therapy.

Keywords: statin, diabetes mellitus, cardiovascular risk.

\section{INTRODUCTION}

Cardiovascular diseases are the leading cause of morbidity and mortality in developed and developing countries. ${ }^{1}$ In Brazil, it is the leading cause of death, with deaths from cerebrovascular disease (mostly by cerebral ischemic stroke) and ischemic heart disease (mostly, acute myocardial infarction - AMI, accounting for $2 / 3$ of cardiovascular deaths - Datasus, 2013). In 2010, the death rate adjusted for age by ischemic myocardial disease in men was $94 / 100,000$, and in women, $62.8 / 100,000$ inhabitants. In the decade from 2000 to 2010, this mortality rate remained practically stable, with no evidence of significant reduction. However, a possible growth in this rate will be observed in the coming years, due to the increase in mortality observed in some regions of the country. ${ }^{2}$

Reducing the socioeconomic impact of cardiovascular diseases, particularly those that have atherosclerosis as their basic pathophysiology, can be achieved in two ways: by better control of risk factors and the improved treatment of the acute disease itself. ${ }^{3}$ Therefore, proper treatment of changes in plasma cholesterol levels is of fundamental importance. The increase in plasma cholesterol is a major risk factor for AMI, ${ }^{4}$ also contributing significantly to vascular involvement in other arterial territories. ${ }^{5}$ Increases in the levels of cholesterol contained in low-density lipoprotein (LDLc) are closely correlated with increased cardiovascular risk, regardless of age. ${ }^{6}$ On the other hand, the reduction of LDLc is clearly associated with risk reduction, particularly with the use of statins. ${ }^{7}$

Statins reduce the concentration of LDLc by inhibiting 3-hydroxy-3-methyl-glutaryl-CoA reductase (HMGCoAR), leading to a proportional reduction in the risk of cardiovascular disease. ${ }^{7-10}$ This reduction in risk is seen in both primary prevention and secondary, as shown in a meta-analysis conducted by the cholesterol treatment tri- 
alists' (CTT) collaboration, which included data on approximately 170,000 individuals from 26 randomized trials (statin $v s$. placebo, or high-dose $v$ s. low-dose statin). ${ }^{7}$ This meta-analysis showed a cardiovascular risk reduction of approximately $20 \%$ for each $39 \mathrm{mg} / \mathrm{dL}$ decrease in LDLc. This risk reduction is achieved with a low incidence of adverse effects. The main side effects with their use are myopathy and myalgia. In extreme cases, there may be rhabdomyolysis, particularly simvastatin $80 \mathrm{mg}$, a dosage already banned in some countries. Treatment with statins was shown to be generally safe and without significant effects on deaths due to cancer or other non-vascular causes. For these reasons, this class of drugs has become the most commonly prescribed in the world. In the United States, over $25 \%$ of adults aged at least 45 years ( 30 million individuals) received statins between 2005 and $2008,{ }^{11}$ and an estimated 56 million may be eligible for treatment with statins under the new American guidelines. ${ }^{12,13}$

In recent years, some evidence suggests that the use of statins may be associated with the emergence of new cases of diabetes, leading to new questions about the safety of these drugs. Data from a meta-analysis of prospective studies, ${ }^{14,15}$ as well as population-based study data confirm this finding. ${ }^{16-18}$ In this review, we try to show the most recent evidence on this subject, but reinforcing the current concept that the benefit in reducing cardiovascular risk with the use of statins in patients eligible for the treatment outweighs the possible risk of developing diabetes.

\section{StATINS AND RISK OF TYPE 2 DIABETES}

Despite the efficacy and adequate safety profile, current evidence suggests the association between the use of statins and the risk of developing type 2 diabetes. Greater attention to the issue has been given since the publication of the Justification for the Use of Statins in Primary Prevention: an Intervention Trial Evaluation Rosuvastatin (JUPITER study), ${ }^{19}$ which showed significant benefit of rosuvastatin compared to placebo in reducing cardiovascular risk in adults without cardiovascular disease or diagnosed diabetes with $\mathrm{LDLc}<130$ $\mathrm{mg} / \mathrm{dL}$ and PCR $\geq 2 \mathrm{mg} / \mathrm{L}$. In this study, we observed an increased number of patients with newly diagnosed diabetes in the group that received statin. This absolute increase was small but statistically significant in the number of reported cases of diabetes. These results of the JUPITER study differed from a post hoc analysis performed by The West of Scotland Coronary Prevention Study (Woscops), ${ }^{20}$ which involved men with significant hypercholesterolemia in primary prevention. In this analysis, there was an absolute decrease of about $1 \%$, and $30 \%$ decrease in relative risk for developing diabetes associated with pravastatin $40 \mathrm{mg} /$ day compared with placebo. The apparently consistent protective effect was attributed by the authors to the possible anti-inflammatory effects of statin. It is true that the number of diabetes cases in the Woscops was relatively small, only 139 new cases, and the diabetes diagnostic criteria were not in accordance with current guidelines. Analysis of studies conducted after the Woscops showed inconsistent relationship between statin use and diabetes. ${ }^{21,22}$ However, more recent analyzes corroborated the findings of the JUPITER study.

In a meta-analysis of 13 studies on statins including over 90,000 individuals, the risk of developing diabetes associated with the use of statins as compared to placebo was $9 \%$ (odds ratio [OR] 1.09; 95CI 1.02-1.17). ${ }^{14}$ Moreover, a meta-regression analysis showed that the risk of developing diabetes with statins is higher in studies with older individuals. In this study, the authors estimated that the treatment of 255 patients with statins for 4 years would result in one extra case of diabetes (number needed to harm - NNH) ${ }^{14}$ In all of the studies involved in the meta-analysis, the population of long-term or recent onset diabetics has the same benefit of decreased cardiovascular morbidity and mortality than the individuals treated with statins who were not pre-diabetic or insulin resistant.

A subsequent meta-analysis evaluated the influence of statin dosage on the incidence of type 2 diabetes, evaluating studies that compared intensive statin therapy and moderate dose therapy. ${ }^{15}$ Five studies and more than 32,000 participants without diagnosed diabetes were included. 2,749 cases of diabetes were identified, 1,449 cases from the group receiving intensive care and 1,300 in the group receiving a moderate treatment, with two additional cases in the intensive treatment group per 1000 patient-years. It is interesting to note that of the 6,684 individuals presenting cardiovascular events, 3,134 were in the intensive group and 3,550 belonged to the moderate treatment group, representing 6.5 cases less in the intensive group per 1000 patient-years in a follow-up of 4.9 years. Thus, in this metaanalysis that included patients with manifest coronary disease, intensive therapy was associated with increased risk of type 2 diabetes compared with moderate therapy (OR 1.12, 95CI 1.04-1.22), but also lower cardiovascular risk (OR 0.84, 95CI 0.75-0.94). ${ }^{15}$

In another meta-analysis, published in 2014, the incidence of type 2 diabetes associated with the use of statin was evaluated once again. 129,170 participants were included from 20 randomized trials with statins (statin $v$ s. control, and high-dose vs. low-dose statin) without a diagnosis of type 2 diabetes at baseline. In this study, the chance of a new diagnosis of type 2 diabetes with the use of statin was $12 \%\left(\mathrm{OR} 1.12\right.$, 95CI 1.06-1.18). ${ }^{23}$ 
An analysis of the JUPITER study suggests that the risk of developing type 2 diabetes using a statin appears limited to individuals who already have baseline conditions that increase the risk of progression to type 2 diabetes, such as abnormal fasting blood glucose or glycosylated hemoglobin, metabolic syndrome, or obesity (Table 1). In this analysis, participants with at least one risk factor for diabetes had their risk of diabetes increased by $28 \%$ with the use of rosuvastatin, which was not observed in subjects who received rosuvastatin but had no risk factor for diabetes (OR 0.99, 95CI 0.45-2.21, $\mathrm{p}=0.99$ ). ${ }^{24}$ Predisposing factors to the development of diabetes identified in this analysis of the JUPITER study were similar to the factors demonstrated in an analysis involving data from three large clinical studies with atorvastatin. ${ }^{25}$

TABLE 1 Risk factors for developing type 2 diabetes with statin.

Older age $^{14}$

Intensive therapy with statin ${ }^{15}$

Metabolic syndrome ${ }^{24}$

High fasting blood glucose ${ }^{24}$

High body mass index ${ }^{24}$

High glycated hemoglobin $\left(\mathrm{HbA}_{1 \mathrm{c}}>6 \%\right)^{24}$

Some studies also suggest that there is variation in the diabetogenic risk of different statins, but the literature is still not completely clear in this respect. In the Pravastatin or Atorvastatin Evaluation and Infection Therapy - Thrombolysis in Myocardial Infarction 22 (Prove it - TIMI22) trial, which included patients with acute coronary syndrome, non-diabetic patients who received atorvastatin compared to those receiving pravastatin had a higher risk of developing HbA1c > $6 \% .{ }^{26}$ Nevertheless, in a meta-analysis by Sattar et al., there was no clear difference in the diabetogenic power among statins, with similar risks between lipophilic and hydrophilic statins. ${ }^{14}$ Results of different studies suggest that pitavastatin may not be associated with diabetogenic effect, but this observation needs to be confirmed by more robust studies. ${ }^{26,27}$

"Real world" data seem to support the increased incidence of diabetes with the use of statins evidenced in randomized clinical trials. In an Italian cohort of 115,709 patients, the risk of diabetes was assessed according to adherence to treatment with statins. Compared to patients with very low treatment adherence (days of use $<25 \%$ ), those with low adherence $(26-50 \%$ ) had a $12 \%$ increase in the risk of developing diabetes; the intermediate adherence (51$75 \%$ ) group had an increased risk of $22 \%$; and those with high adherence (using> 75\%) had a $32 \%$ increase in risk. That is, the risk of new cases of diabetes increased to the extent that the adherence to treatment with statins was more evident. ${ }^{28}$ Regarding the intensity of treatment with statins, real-world data disagree on the possibility of whether or not there is a relationship between intensity and risk of developing diabetes, as measured in a study that analyzed more than 170,000 patients aged 65 years or older in Ontario, Canada, hospitalized for myocardial infarction between 2004 and 2010. Just over 52\% of patients received statins at higher doses (atorvastatin $>40 \mathrm{mg}$, rosuvastatin> $20 \mathrm{mg}$ or simvastatin $>60 \mathrm{mg}$ ). A total of 8,540 patients were matched and analyzed according to the intensity of treatment. Five years after hospitalization for myocardial infarction, $13.6 \%$ of patients receiving high-dose statins had a new diagnosis of diabetes. In contrast, $13 \%$ of those receiving moderate doses of statins had a new diagnosis of diabetes. The difference was not statistically significant. Therapy with high-dose statin was associated with a significant decrease in the risk of hospitalization for acute coronary syndrome or death compared to therapy with moderate doses of statin. This study provides evidence that high-dose statins are underutilized in the elderly with no significant increase in the incidence of diabetes. ${ }^{29}$

Another study, also with analysis of population data base of Ontario, assessed the risk of developing diabetes with various statins compared to pravastatin. Data from 471,250 non-diabetic patients, aged over 65 years and who began treatment with statin over a period of 14 years (1 August 1997 to 31 March 2010) were analyzed. Atorvastatin was the most prescribed drug, accounting for half of all new prescriptions, followed by rosuvastatin, simvastatin, pravastatin, lovastatin and fluvastatin. Atorvastatin, rosuvastatin and simvastatin were associated with an increased risk of new cases of diabetes compared to treatment with pravastatin of 22,18 and $10 \%$, respectively. There was no increased risk of diabetes with lovastatin or fluvastatin in this study. ${ }^{16}$

\section{Possible mechanisms of DIABetogenicity OF STATINS}

Since the finding of the diabetogenic effect of statins, there has been great interest in the possible mechanisms for this phenomenon. However, these still remain unclear. ${ }^{26}$ Type 2 diabetes develops through a combination of insulin resistance and progressive dysfunction of beta cells. Studies on the effects of statin treatment on insulin sensitivity are conflicting and generally small. ${ }^{30-34}$ Treatment with simvastatin and rosuvastatin has been shown to decrease insulin sensitivity, while treatment with pravastatin improved 
insulin sensitivity. ${ }^{35,36}$ Reduction of insulin secretion caused by statin has been reported in some in vitro studies, ${ }^{37}$ but other studies in this model showed no such decrease. ${ }^{38}$

Data from large meta-analyzes assessing the risk of developing diabetes with statins, either compared to placebo ${ }^{14}$ or compared to a less intensive treatment, ${ }^{15}$ suggest a causal relationship. Biases that could act as a confounding factors in this analysis are few. One suggestion was that the survival bias could explain the findings. Another explanation would be that patients included in large studies with significant reduction of LDL can become complacent, changing their lifestyles to less healthy habits, gaining weight and developing diabetes. JUPITER data show that the average weight of patients treated with rosuvastatin increased by $0.3 \mathrm{~kg}$ as compared to those receiving placebo. ${ }^{19}$ Nevertheless, a significant increase in the risk of developing diabetes probably could not be explained by this slight weight gain.

In order to evaluate if the relationship between statins and diabetes could be directly correlated with the inhibition of HMGCoAR, the main therapeutic target of statins, Swerdlow et al. ${ }^{23}$ used the principle of Mendelian randomization and examined the effect of two single nucleotide polymorphisms (SNPs) in the gene of HMGCoAR on body weight and risk of type 2 diabetes. The results showed that, similarly to statins in clinical trials, the HMGCoAR variants that were assessed had an association with higher body weight and risk of type 2 diabetes. This implies, at least partially, that HMGCoAR inhibition is a causative factor of metabolic effects observed. However, although the increase in body weight can determine a worsening of insulin resistance and increased risk of type 2 diabetes, the magnitude of weight gain observed both in clinical trials with statins and in genetic studies seems insufficient to fully justify the risk of diabetes. For example, intensive treatment with statin was not associated with a stronger effect on body weight than mild or moderate doses of statin, despite the higher risk of diabetes associated with intensive care. Thus, it is possible that there are also other mechanisms involved in diabeto-genicity of statins, including modulation of HMGCoAR at other sites, such as skeletal muscle, and off-target effects of statins. It seems plausible, therefore, that one or more specific molecular mechanisms exist, although other possibilities such as changes in body composition need to be considered. The possibility of bias, especially in the context of clinical trials, should be considered: patients treated with statins may experience more side effects, leading them to seek medical attention with a greater chance of being diagnosed for diabetes. ${ }^{39}$
There are numerous gaps that need to be answered in addition to any specific mechanism. A particularly important issue is that of macrovascular and microvascular complications of statin-induced diabetes. The increased risk of diabetic complications is described in the study of Mansi et al., who conducted a retrospective cohort study among users of an American health provider between October 2003 and March 2012. 25,970 patients identified as healthy adults (3,982 treated with statins and 21,988 who did not use the drug) were selected. Of these, 3,351 users of statins and 3,351 nonusers were matched according to 42 baseline characteristics, which generated a propensity score. Thus, statin users had higher chances of new cases of diabetes (OR 1.87; CI95\% 1.67-2.01) and diabetic complications (OR 2.50; CI95\% 1.88-3.32). ${ }^{40}$

\section{Diabetogenicity of statins vs. Cardiovascu- LAR RISK REDUCTION (TABLE 2)}

Despite the diabetogenic effect, statins remain as an important therapeutic pillar for cardiovascular risk reduction. According to current evidence, in the case of individuals with a recommendation for the use of statins, especially those with moderate or high risk, their cardiovascular benefit outweighs the potential risk, even at high doses. In a meta-analysis by Preiss et al., the authors found an additional case of diabetes at every 498 patients treated for 1 year with intensive statin therapy ( $v s$. moderate therapy), compared to 1 patient less presenting a cardiovascular event at every 155 patients treated for 1 year. ${ }^{15}$ These data suggest a wide advantage of using high-dose statin in patients for secondary prevention.

Individuals in primary prevention, analyzed by the JUPITER study, for example, also had significantly greater cardiovascular benefits compared to the risks of using statins. In analysis restricted to 486 participants who developed diabetes during follow-up (270 in the rosuvastatin group vs. 216 in the placebo group), the reduction of cardiovascular risk associated with the use of statin was 37\% (hazard ratio [HR] 0.63, 95CI 0.25-1.60), consistent with that observed in the study as a whole $(0.56,0.46-0.69)$. In diabetic patients, the benefit of statins has also been demonstrated. In the CTT's meta-analysis, the relative reduction in cardiovascular risk of approximately $20 \%$ at each reduction of LDLc of $39 \mathrm{mg} / \mathrm{dL}$ was consistent between individuals with or without type 2 diabetes mellitus.

\section{Conclusion}

A review of the current scientific literature suggests a consistent association between statin use and increased risk of developing type 2 diabetes. This association is stronger in the elderly, with the use of higher doses of the drug, 
TABLE 2 Risk of type 2 diabetes and relative reduction of cardiovascular risk with statin.

\begin{tabular}{|c|c|c|c|}
\hline Study & Characteristics & Risk of type 2 diabetes & Relative reduction of CV risk \\
\hline Sattar et al. ${ }^{14}(n=91,140)$ & Statin vs. control & 9\% (OR 1.09; 95Cl 1.02-1.17) & Not available \\
\hline \multicolumn{4}{|l|}{ Meta-analysis (13 studies) } \\
\hline Swerdlow et al. ${ }^{23}(n=129,170)$ & Statin vs. control or high-dose vs. & $12 \%(\mathrm{OR} 1.12,95 \mathrm{Cl} 1.06-1.18)$ & Not available \\
\hline Meta-analysis (20 studies) & low-dose statin & & \\
\hline Preiss et al. ${ }^{15}(n=32,752)$ & Secondary prevention & $12 \%(\mathrm{OR} 1.12,95 \mathrm{Cl} 1.04-1.22)$ & $-16 \%($ OR $0.84,95 \mathrm{Cl} 0.75-0.94)$ \\
\hline Meta-analysis ( 5 studies) & (high-dose vs. low-dose statin) & & \\
\hline \multirow{3}{*}{$\begin{array}{l}\text { Ridker et al. }{ }^{24}(n=17,603) \\
\text { JUPITER study }\end{array}$} & Primary prevention and $\geq 1 \mathrm{RF}$ for & $28 \%$ (HR 1.28; 95CI 1.07-1.54) & $-39 \%$ (HR $0.61 ; 95 \mathrm{Cl} 0.47-0.79)$ \\
\hline & diabetes & & \\
\hline & $\begin{array}{l}\text { Primary prevention and no RF for } \\
\text { diabetes }\end{array}$ & $-1 \%(\mathrm{HR} 0.99 ; 95 \mathrm{Cl} 0.45-2.21)$ & $-52 \%(\mathrm{HR} 0.48 ; 95 \mathrm{Cl} 0.33-0.68)$ \\
\hline
\end{tabular}

CV: cardiovascular; OR: odds ratio; HR: hazard ratio; RF: risk factor; JUPITER: Justification for Use of statins in Prevention: an Intervention Trial Evaluating Rosuvastatin.

and the presence of metabolic risk factors for development of diabetes. However, the same literature demonstrates that the cardiovascular benefits of statins outweigh its risks in patients with an indication to receive lipid-lowering therapy.

There are some knowledge gaps in this area that still need to be clarified. We do not know, for instance, what happens with the risk of developing diabetes if treatment is stopped. Nor do we know if the therapy with statins leads to worsening of glycemic control in people with diabetes or the need for intensification of glucose-lowering therapy, although the available data suggest that these changes are less significant. Another relevant issue would be to understand if the effect of statin on recent-onset diabetes can be exacerbated by other cardiovascular drugs with similar metabolic effects, such as thiazide diuretics, or beta blockers. Similarly, we do not know if this effect could be alleviated by drugs, such as inhibitors of angiotensin converting enzyme or angiotensin II receptor antagonists.

In conclusion, the decision whether to prescribe a statin, as well as the intensity of the treatment to be adopted, should not be affected by the issue of diabeto-genicity. However, it is very important to educate patients about this effect, especially regarding the importance of lifestyle changes that can certainly minimize the risk.

\section{Resumo}

Uso de estatinas e a incidência de diabetes mellitus tipo 2

Introdução: o uso de estatinas está associado à redução do risco cardiovascular em estudos de prevenção primária e secundária, e essa redução ocorre de modo diretamente proporcional à redução de LDL-colesterol. Evidências recentes sugerem que estatinas podem estar associadas à maior incidência de novos casos de diabetes. O objetivo desta revisão é identificar os fatores associados ao aumento de risco e os potenciais mecanismos diabetogênicos das estatinas. Além disso, avaliou-se se o risco de diabetes interfere na redução de risco cardiovascular obtida com as estatinas.

Métodos: foram revisados artigos publicados nas bases de dados Scielo e Pubmed, que avaliaram ou descreveram a associação do uso de estatinas com o risco de diabetes até junho de 2015.

Resultados: o uso de estatinas está associado a um pequeno aumento na incidência de novos casos de diabetes. Idade, potência do tratamento com estatina, presença de síndrome metabólica, glicemia de jejum alterada, excesso de peso e hemoglobina glicada previamente alterada estão associados a um maior risco de diabetes, mas não há consenso sobre os possíveis mecanismos diabetogênicos das estatinas. Nos pacientes candidatos à terapêutica hipolipemiante, o benefício de redução do risco cardiovascular supera qualquer aumento de risco na incidência de diabetes.

Conclusão: estatinas estão associadas a um pequeno aumento na incidência de diabetes em pacientes predispostos a alterações glicêmicas. Entretanto, como persiste, mesmo nesse grupo, o benefício da redução de risco cardiovascular, não há qualquer evidência até o momento de que esse achado deva mudar a decisão de iniciar o tratamento com estatinas.

Palavras-chave: estatina, diabetes mellitus, risco cardiovascular.

\section{References}

1. Eagle KA, Blank DJ, Aguiar E, Firth LM. Economic impact of regression of left ventricular hypertrophy by antihypertensive drugs. J Hum Hypertens. 1993; 7(4):341-51. 
2. Baena CP, Chowdhury R, Schio NA, Sabbag Jr AE, Guarita-Souza LC, Olandoski M, et al. Ischaemic heart disease deaths in Brazil: current trends, regional disparities and future projections. Heart. 2013; 99(18):1359-64.

3. Ford ES, Ajani UA, Croft JB, Critchley JA, Labarthe DR, Kottke TE, et al. Explaining the decrease in U.S. deaths from coronary disease, 1980-2000. N Engl J Med. 2007; 356(23):2388-98.

4. Yusuf S, Hawken S, Ounpuu S, Dans T, Avezum A, Lanas F, et al. Effect of potentially modifiable risk factors associated with myocardial infarction in 52 countries (the INTERHEART study): case-control study. Lancet. 2004; 364(9438):937-52.

5. O'Donnell MJ, Xavier D, Liu L, Zhang H, Chin SL, Rao-Melacini P, et al. Risk factors for ischaemic and intracerebral haemorrhagic stroke in 22 countries (the INTERSTROKE study): a case-control study. Lancet. 2010; 376(9735):112-23.

6. Prospective Studies Collaboration; Lewington S, Whitlock G, Clarke R, Sherliker $\mathrm{P}$, Emberson J, et al. Blood cholesterol and vascular mortality by age, sex, and blood pressure: a meta-analysis of individual data from 61 prospective studies with 55,000 vascular deaths. Lancet. 2007; 370(9602):1829-39.

7. Cholesterol Treatment Trialists' (CTT) Collaboration, Baigent C, Blackwell L, Emberson J, Holland LE, Reith C, et al. Efficacy and safety of more intensive lowering of LDL cholesterol: a meta-analysis of data from 170,000 participants in 26 randomised trials. Lancet. 2010; 376(9753):1670-81.

8. O'Regan C, Wu P, Arora P, Perri D, Mills EJ. Statin therapy in stroke prevention: a meta-analysis involving 121,000 patients. American J Med. 2008; 121(1):24-33.

9. Cholesterol Treatment Trialists' (CTT) Collaborators, Mihaylova B, Emberson J, Blackwell L, Keech A, Simes J, et al. The effects of lowering LDL cholesterol with statin therapy in people at low risk of vascular disease: meta-analysis of individual data from 27 randomised trials. Lancet. 2012; 380(9841):581-90.

10. Cholesterol Treatment Trialists' (CTT) Collaborators, Kearney PM, Blackwell L, Collins R, Keech A, Simes J, et al. Efficacy of cholesterol-lowering therapy in 18,686 people with diabetes in 14 randomised trials of statins: a metaanalysis. Lancet. 2008; 371(9607):117-25.

11. National Center for Health S. Health, United States. Health, United States, 2010: With Special Feature on Death and Dying. Hyattsville (MD): National Center for Health Statistics (US), 2011.

12. Pencina MJ, Navar-Boggan AM, D’Agostino Sr RB, Williams K, Neely B, Sniderman AD, et al. Application of new cholesterol guidelines to a population-based sample. N Engl J Med. 2014; 370:1422-31.

13. Stone NJ, Robinson J, Lichtenstein AH, Merz CNB, Blum CB, Eckel RH, et al. 2013 ACC/AHA guideline on the treatment of blood cholesterol to reduce atherosclerotic cardiovascular risk in adults: a report of the American College of Cardiology/American Heart Association Task Force on Practice Guidelines. J Am Coll Cardiol. 2014; 63(25 Pt B):2889-934.

14. Sattar N, Preiss D, Murray HM, Welsh P, Buckley BM, de Craen AJ, et al. Statins and risk of incident diabetes: a collaborative meta-analysis of randomised statin trials. Lancet. 2010; 375(9716):735-42.

15. Preiss D, Seshasai SR, Welsh P, Murphy SA, Ho JE, Waters DD, et al. Risk of incident diabetes with intensive-dose compared with moderate-dose statin therapy: a meta-analysis. JAMA. 2011; 305(24):2556-64.

16. Carter AA, Gomes T, Camacho X, Juurlink DN, Shah BR, Mamdani MM. Risk of incident diabetes among patients treated with statins: population based study. BMJ. 2013; 346:f2610.

17. Navarese EP, Buffon A, Andreotti F, Kozinski M, Welton N, Fabiszak T, et al. Meta-analysis of impact of different types and doses of statins on newonset diabetes mellitus. American J Cardiol. 2013; 111(8):1123-30.

18. Danaei G, Garcia Rodriguez LA, Fernandez Cantero O, Hernan MA. Statins and risk of diabetes: an analysis of electronic medical records to evaluate possible bias due to differential survival. Diabetes Care. 2013; 36(5):1236-40.

19. Ridker PM, Danielson E, Fonseca FA, Genest J, Gotto AM, Jr., Kastelein JJ, et al. Rosuvastatin to prevent vascular events in men and women with elevated C-reactive protein. N Engl J Med. 2008; 359(21):2195-207.

20. Freeman DJ, Norrie J, Sattar N, Neely RD, Cobbe SM, Ford I, et al. Pravastatin and the development of diabetes mellitus: evidence for a protective treatment effect in the West of Scotland Coronary Prevention Study. Circulation. 2001; 103(3):357-62.
21. Keech A, Colquhoun D, Best J, Kirby A, Simes RJ, Hunt D, et al. Secondary prevention of cardiovascular events with long-term pravastatin in patients with diabetes or impaired fasting glucose: results from the LIPID trial. Diabetes Care. 2003; 26(10):2713-21.

22. Coleman CI, Reinhart K, Kluger J, White CM. The effect of statins on the development of new-onset type 2 diabetes: a meta-analysis of randomized controlled trials. Curr Med Res Opin. 2008; 24(5):1359-62.

23. Swerdlow DI, Preiss D, Kuchenbaecker KB, Holmes MV, Engmann JE, Shah $\mathrm{T}$, et al. HMG-coenzyme A reductase inhibition, type 2 diabetes, and bodyweight: evidence from genetic analysis and randomised trials. Lancet. 2015; 385(9965):351-61.

24. Ridker PM, Pradhan A, MacFadyen JG, Libby P, Glynn RJ. Cardiovascular benefits and diabetes risks of statin therapy in primary prevention: an analysis from the JUPITER trial. Lancet. 2012; 380(9841):565-71.

25. Waters DD, Ho JE, DeMicco DA, Breazna A, Arsenault BJ, Wun C-C, et al Predictors of new-onset diabetes in patients treated with atorvastatin: results from 3 large randomized clinical trials. J Am Coll Cardiol. 2011; 57(14):1535-45.

26. Sattar N, Taskinen MR. Statins are diabetogenic--myth or reality? Atheroscler Suppl. 2012; 13(1):1-10

27. Kawai Y, Sato-Ishida R, Motoyama A, Kajinami K. Place of pitavastatin in the statin armamentarium: promising evidence for a role in diabetes mellitus. Drug Des Devel Ther. 2011; 5:283-97.

28. Corrao G, Ibrahim B, Nicotra F, Soranna D, Merlino L, Catapano AL, et al. Statins and the risk of diabetes: evidence from a large population-based cohort study. Diabetes Care. 2014; 37(8):2225-32

29. Ko DT, Wijeysundera HC, Jackevicius CA, Yousef A, Wang J, Tu JV. Diabetes mellitus and cardiovascular events in older patients with myocardial infarction prescribed intensive-dose and moderate-dose statins. Circ Cardiovasc Qual Outcomes. 2013; 6(3):315-22.

30. Altunbas H, Balci MK, Karayalcin U. No effect of simvastatin treatment on insulin sensitivity in patients with primary hypercholesterolemia. Endocr Res. 2003; 29(3):265-75.

31. Bellia A, Rizza S, Galli A, Fabiano R, Donadel G, Lombardo MF, et al. Early vascular and metabolic effects of rosuvastatin compared with simvastatin in patients with type 2 diabetes. Atherosclerosis. 2010; 210(1):199-201.

32. Paniagua JA, Lopez-Miranda J, Escribano A, Berral FJ, Marin C, Bravo D, et al. Cerivastatin improves insulin sensitivity and insulin secretion in earlystate obese type 2 diabetes. Diabetes. 2002; 51(8):2596-603.

33. Szendroedi J, Anderwald C, Krssak M, Bayerle-Eder M, Esterbauer H, Pfeiler $\mathrm{G}$, et al. Effects of high-dose simvastatin therapy on glucose metabolism and ectopic lipid deposition in nonobese type 2 diabetic patients. Diabetes Care. 2009; 32(2):209-14

34. ter Avest E, Abbink EJ, de Graaf J, Tack CJ, Stalenhoef AF. Effect of rosuvastatin on insulin sensitivity in patients with familial combined hyperlipidaemia. Eur J Clin Invest. 2005; 35(9):558-64.

35. Baker WL, Talati R, White CM, Coleman CI. Differing effect of statins on insulin sensitivity in non-diabetics: a systematic review and meta-analysis. Diabetes Res Clin Pract. 2010; 87(1):98-107.

36. Moutzouri E, Liberopoulos E, Mikhailidis DP, Kostapanos MS, Kei AA, Milionis $\mathrm{H}$, et al. Comparison of the effects of simvastatin vs. rosuvastatin vs. simvastatin/ezetimibe on parameters of insulin resistance. Int J Clin Pract. 2011; 65(11):1141-8.

37. Yada $T$, Nakata M, Shiraishi $T$, Kakei M. Inhibition by simvastatin, but not pravastatin, of glucose-induced cytosolic $\mathrm{Ca} 2+$ signalling and insulin secretion due to blockade of L-type Ca2+ channels in rat islet beta-cells. Br J Pharmacol. 1999; 126(5):1205-13

38. Ishikawa M, Okajima F, Inoue $\mathrm{N}$, Motomura $\mathrm{K}$, Kato $\mathrm{T}$, Takahashi A, et al. Distinct effects of pravastatin, atorvastatin, and simvastatin on insulin secretion from a beta-cell line, MIN6 cells. J Atheroscler Thromb. 2006; 13(6):329-35.

39. Preiss D, Sattar N. Statins and the risk of new-onset diabetes: a review of recent evidence. Curr Opin Lipidol. 2011; 22(6):460-6.

40. Mansi I, Frei CR, Wang CP, Mortensen EM. Statins and New-Onset Diabetes Mellitus and Diabetic Complications: A Retrospective Cohort Study of US Healthy Adults. J Gen Intern Med. 2015. [Epub ahead of print] 